\title{
A New Preparation of Highly Functionalized Aromatic and Heteroaromatic \\ Zinc and Copper Organometallics
}

\author{
Tahir N. Majid and Paul Knochel* \\ The Willard H. Dow Laboratories, Department of Chemistry, The University of Michigan \\ Ann Arbor, Michigan 48109
}

Summary: Functionalized aromatic iodides possessing an ester, cyano, chloride or keto group can be converted to arylzinc iodides by reaction with zinc in DMF or DMAC. After transmetallation to the corresponding arylcopper, they react with several electrophiles such as enones, altylic halides and benzoyl chloride to afford highty

functionalized aromatic compounds. Extension to the preparation of polyfunctionalized heteroaromatic zinc iodides and to an alkenylzinc iodide was also successful, although the zinc insertion to a pure (E)-alkenyl iodide furnished an E/Z mixture of alkenyl zinc iodides.

We have recently shown that various highly functionalized alkyl iodides ${ }^{1}$ or bromides ${ }^{2}$ and benzylic halides ${ }^{3}$ readily insert zinc in THF under mild conditions $\left(5-50^{\circ} \mathrm{C}, 0.5-12 \mathrm{~h}\right)$, affording polyfunctional zinc organometallics. Unfortunately, $\mathrm{sp}^{2}$-bonded iodides were inert under these conditions; it was reported that only highly activated zinc powder ${ }^{4}$ reacted with bromobenzene in 1,2-dimethoxyethane $\left(85^{\circ} \mathrm{C}, 10 \mathrm{~h}, 73 \%\right.$ reaction). The use of more polar solvents such as dibutyl phosphate or diethyl carbonate allowed the formation of phenylzinc iodide from iodobenzene and zinc, albeit in moderate yields $(10-35 \%) .^{5}$ More successful was the related direct insertion of highly activated cadmium ${ }^{6}$ and copper $^{7}$ powders to aromatic halides which made possible the preparation of polyfunctional organocopper reagents. We now wish to report that various functionalized aromatic zinc iodides 1 can be prepared under relatively mild conditions $\left(25-55^{\circ} \mathrm{C}\right)$ in fair to good yields from the corresponding iodides 2 if the reaction is performed in $\mathrm{N}, \mathrm{N}$-dimethylformamide (DMF) or N,N-dimethyl-

Scheme I

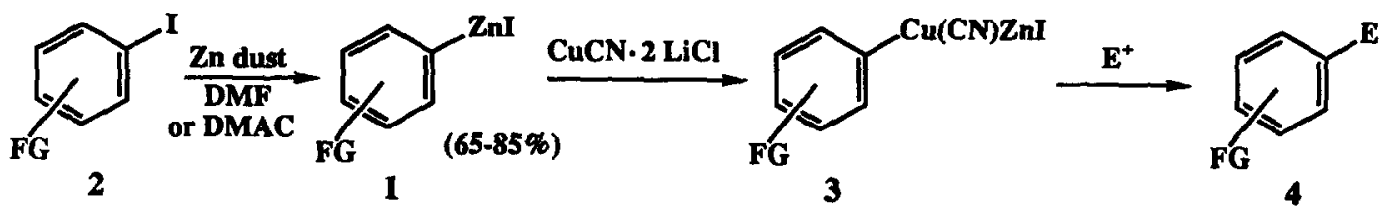

acetamide (DMAC). 8 After the addition of the THF soluble salt CuCN.2 LiCl, copper organometallics of type 3 are formed which react in good to excellent yields with a variety of organic electrophiles (Scheme I and Table I). The aromaric ring substituents strongly influence the rate of the zinc insertion. Thus, whereas iodobenzene (entries 1 and 2) requires a reaction time of $22 \mathrm{~h}$ at $55^{\circ} \mathrm{C}$ (80\% conversion) $)^{9}$, 2-iodobenzonitrile (entries 3 and 4) undergoes complete insertion within $2 \mathrm{~h}$ at $35^{\circ} \mathrm{C}$ ( $80 \%$ conversion). A comparison between the zinc insertion rates of $o$-, $m$-, and $p$-iodobenzonitriles indicates that 0 -iodobenzonitrile reacts significantly faster, thus the respective $t_{1 / 2}$ at $30^{\circ} \mathrm{C}$ are: $t_{1 / 2}($ ortho $)<5$ min; $t_{1 / 2}($ meta $)=40$ $\min ; t_{1 / 2}($ para $)=30 \mathrm{~min} .10$ Ethyl 3-iodobenzoate inserts zinc slightly slower than the cyano-substitured iodobenzenes (80\% conversion after $5 \mathrm{~h}$ at $45{ }^{\circ} \mathrm{C}$, entries 8 and 9) whilst aromatic ketones furnish the corresponding zinc organometallic 
within $4 \mathrm{~h}$ at $40-45^{\circ} \mathrm{C}$ (entries 11-13). It must be mentioned that 2-iodobenzophenone afforded the zinc reagent $3 f$ in low yields ( $35 \%$ by iodolysis), whereas 2 -iodophenyl cyclohexyl ketone could be converted to the corresponding zinc compound $3 \mathrm{~g}$ in over $64 \%$ yield. The copper reagents formed after treatment with $\mathrm{CuCN} \cdot 2 \mathrm{LiCl}$ reacted with various electrophiles such as allylic bromides and iodides ${ }^{11}$ (entries $1,3,5,8,10,11$ and 13 ), enones (entries 2,6,7, and 12) and benzoyl chloride (entries 4,9), 12 leading to polyfunctional aromatic molecules of type 4 in 61-93\% yield (Table I). ${ }^{13}$ We also found that this reaction could be applied to the preparation of polyfunctional hetero-aromatic zinc iodides. Thus treatment of 2-iodothiophene $5 \mathrm{a}$ with zinc dust at room temperature in DMAC provides, after $1.5 \mathrm{~h}$, the corresponding zinc organometallic $6 \mathrm{a}$ in $60 \%$ yield. Clearly, the presence of a sulfur atom in an $\alpha$-position to the carbon-iodine bond strongly enhances the rate of formation of zinc reagents 6. After transmetallation to the copper derivative treatment with 3-iodo-2-cyclohexenone $\left(-60^{\circ} \mathrm{C}\right.$; then $0^{\circ} \mathrm{C}, 15 \mathrm{~h}$; then $20^{\circ} \mathrm{C}, 6 \mathrm{~h}$ ) afforded 3-(2-thienyl)cyclohexenone 7a in 78\% yield. Furthermore, the same reaction sequence could be performed with 5-benzoyl-2-iodothiophene $5 b$ to furnish the polyfunctional thiophene $7 \mathrm{~b}$ in high yield (88\%) (Scheme I). Extensions to the preparation of alkenylzinc iodides was also

Scheme II

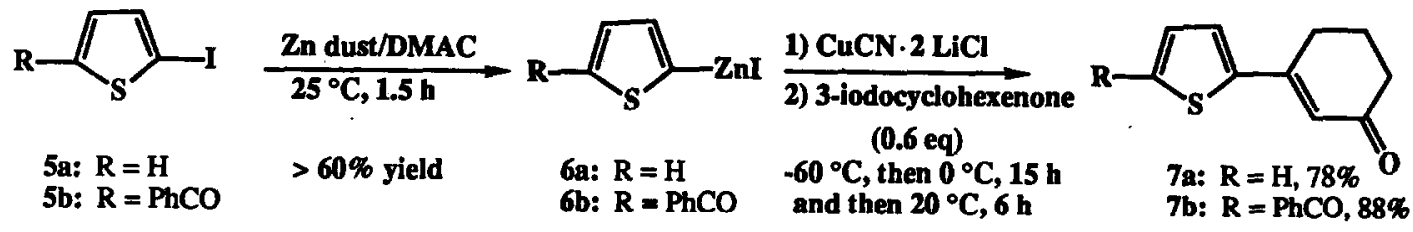

possible, although harsher reaction conditions were found to be necessary. Thus the reaction of pure (E)-1-iodo-1-octene with zinc dust in DMF at $70{ }^{\circ} \mathrm{C}$ for $14 \mathrm{~h}$ afforded a mixture of octenylzinc iodides (1:1 to $1.5: 1$ trans/cis). After transmetallation to the copper organometallic 8, allylation with tert-butyl $\alpha$-(bromomethyl)acrylate or Michael-addition to ethyl benzylidenemalonate gave the desired products 9 and 10 in $72 \%$ and $87 \%$ yield, respectively, as mixtures of $E$ and $Z$ isomers (Scheme III).

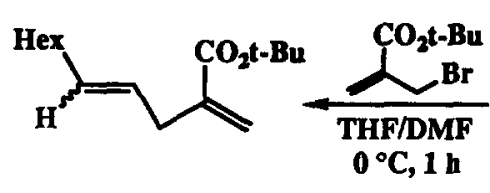

9: $72 \% ; E / Z=50 / 50$
Scheme III

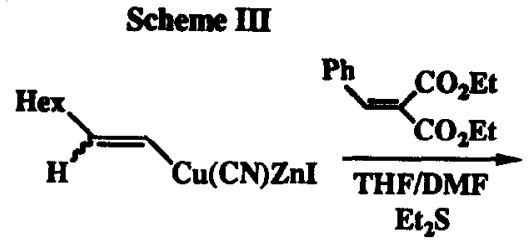

8<smiles>CCOC(=O)C(C(=O)OCC)C(/C=C\c1ccccc1)c1ccccc1</smiles>

10: $87 \% ; E / Z=65 / 35$

The preparation of other classes of highly functionalized heterocyclic and alkenyl-zinc compounds is currently underway in our laboratories.

Acknowledgment: We thank the National Institutes of Health (GM 41908) for their generous support of this work.

References and Notes:

1. (a) Knochel, P.; Yeh, M.C.P.; Berk, S.C.; Talbert, J. J. Org. Chem. 1988, 53, 2390; (b) Yeh, M.C.P., Knochel, P. Tetrahedron Lett. 1988, 29, 2395.

2. Retherford, C., Chou, T.-S., Schelkun, R.M.; Knochel, P. Tetrahedron Lett. 1990, 31, 1833.

3. Berk, S.C.; Knochel, P.; Yeh, M.C.P. J. Org. Chem. 1988, 53, 5789.

4. (a) Rieke, R.D.; Uhm, S.J.; Hudnall, P.M. J. Chem. Soc. Chem. Commun. 1973, 269; (b) Rieke, R.D.; Uhm, S.J. Synthesis 1975, 452; (c) Rieke, R.D.; Li, P.T.-J.; Burns, T.P.; Uhm, S.T. J. Org. Chem. 1981, 46, 4323.

5. Grondin, J.; Sebban, M.; Vottero, P.; Blancou, H.; Commeyras, A. J. Organomet. Chem. 1989, 362, 237.

6. Rieke, R.D.; Burkhardt, E.R. J. Org. Chem. 1985, 50, 416. 
Table I. Products of Type 4 Obtained by the Reaction of Polyfunctional Aromatic Zinc and Copper Reagents 3a-3g with Organic Electrophiles. a

\begin{tabular}{|c|c|c|c|c|}
\hline Entry & Aromatic Zinc-Copper & Electrophile & Product & Yield $\left(\Phi_{0}\right)^{a}$ \\
\hline 1 & 3a $\mathrm{PhCu}(\mathrm{CN}) \mathrm{ZnI}$ & & $4 a$ & 80 \\
\hline 2 & $3 \mathbf{a}$ & cyclohexenone & $4 b$ & $93^{b}$ \\
\hline 3 & $\mathbf{3 b}$ & & $4 c$ & 72 \\
\hline 4 & 3b & $\mathrm{PhCOCl}$ in DMF & $4 d$ & 67 \\
\hline 5 & $3 c$ & & $4 e$ & 91 \\
\hline 6 & $3 c$ & & $4 f$ & $61^{b}$ \\
\hline 7 & $3 c$ & & $4 g$ & 64 \\
\hline 8 & 3d & & $4 h$ & 72 \\
\hline 9 & 3d & PhCod & $4 i$ & $67^{c}$ \\
\hline 10 & $3 \mathbf{e}$ & & 4 & 83 \\
\hline 11 & $3 \mathbf{f}$ & & 4h & $83 \mathrm{C}$ \\
\hline
\end{tabular}


Table I (cont'd)

\section{Entry Aromatic Zinc-Copper}

Eloctrophile

Product

Yield (\%)

12

$3 f$<smiles>O=C(c1ccccc1)c1ccccc1C=[W]</smiles>

13<smiles>O=C(O)c1ccccc1C(=O)C1CCCCC1</smiles><smiles>O=C1C=C(I)CCC1</smiles>

4<smiles>O=C1C=C(c2ccccc2C(=O)c2ccccc2)CCC1</smiles>

m<smiles>C[C@@H](Cc1ccccc1C(=O)O[C@H](C)C(=O)O)C1CCCCC1</smiles>

a All yields refer to isolated yields of analytically pure products. Satisfactory spectral data $\left(\mathrm{IR},{ }^{1} \mathrm{H}\right.$ and ${ }^{13} \mathrm{C}$ NMR, mass spectra, high resolution mass spectra) have been obtained for all compounds. All reactions were performed in DMF, unless otherwise indicated

b The reaction was performed in the presence of $\mathrm{Me}_{3} \mathrm{SiCl}(2 \mathrm{eq}$.$) .$

c N,N-dimethylacetamide (DMAC) was used as solvent.

7. (a) Wu, T.-C.; Wehmeyer, R.M.; Rieke, R.D. J. Org. Chem. 1987, 52, 5057; (b) Wehmeyer, R.M.; Rieke, R.D. Tetrahedron Lett. 1988, 29, 4513; (c) Ebert, G.W.; Rieke, R.D. J. Org. Chem. 1988, 53, 4482; (d) O'Brien, R.A.; Rieke, R.D. J. Org. Chem. 1990, 55, 788; for a review, see: Rieke, R.D. Science 1989, 246, 1260.

8. (a) Zakharkin, L.I.; Ikhlobystin, Izv. Akad. Nauk. SSSR., Otd. Khim. Nauk. 1963, 193; (b) Tamaru, Y.; Ochiai, H.; Nakamura, T.; Tsubaki, K.; Yoshida, Z. Tetrahedron Lett. 1985, 26, 5559.

9. Although GLC analysis of a hydrolyzed reaction aliquot indicates the amount of starting iodide consumed, an iodolysis of a reaction aliquot was found to be a more accurate way to determine the actual amount of organozinc iodide formed.

10. Interestingly, this difference between the zinc insertion rates correlates with the difference between the half-wave potentials obtained from cyclic voltammetry experiments performed on the related chloro- and bromobenzonitriles (Bartak, D.E.; Houser, K.J.; Rudy, B.C.; Hawley, M.D. J. Am. Chem. Soc. 1972, 94, 7526). Thus 2-chlorobenzonitrile $\left(E_{1 / 2}=-1.80 \mathrm{~V}\right)$ is reduced significantly easier than the other two isomers $\left(E_{1 / 2}(\mathrm{meta})=-1.91 \mathrm{~V}\right.$ and $E_{1 / 2}$ (para) $=-1.88 \mathrm{~V}$ ), suggesting that the rate determining step of the zinc insertion is an initial one electron transfer from zinc to the aromatic ring.

11. tert-Butyl $\alpha$-(bromomethyl)acrylate was prepared according to: Villieras, J.; Rambaud, M. Synthesis $1982,924$. 2-(Iodomethyl)-3,5-dioxa-1-hexene was prepared according to: Gu, X.-P.; Okuhara, T.; Ikeda, I.; Okahara, M. Synthesis 1988, 535.

12. Benzoyl chloride did not react directly with $3 \mathrm{~b}$, but rather it activated DMF by forming an immonium salt $\left(\mathrm{HC}(\mathrm{OCOPh})=\mathrm{NMe}_{2}{ }^{+} \mathrm{Cl}^{-}\right)$which led to 4d. The use of DMAC instead of DMF suppressed this reaction and afforded the desired benzoylated product, 2-cyanobenzophenone, in $50 \%$ isolated yield (see also entry 9).

13. Typical procedure: Preparation of 2-(2-tert-butoxycarbonyl-2-propenyl)phenyl cyclohexyl ketone 4m (entry 13, Table

I): A $50 \mathrm{~mL}$, three-necked flask equipped with a dropping funnel, a thermometer and an argon inlet was charged with zinc dust (Aldrich, $-325 \mathrm{mesh} ; 0.82 \mathrm{~g}, 12.5 \mathrm{mmol}$ ) in $2 \mathrm{~mL}$ of dry DMF. After zinc activation with dibromoethane (ca. $200 \mathrm{mg}$; see ref. la), the zinc suspension was heated to $45-50^{\circ} \mathrm{C}$ (internal temperature) with an oil bath and a solution of 2-iodophenyl cyclohexyl ketone $(1.5 \mathrm{~g} ; 5 \mathrm{mmol})$ in $4 \mathrm{~mL}$ of DMF containing $50 \mathrm{mg}$ of undecane (internal standard) was slowly added over $40 \mathrm{~min}$. After $4 \mathrm{~h}$ at $45-50^{\circ} \mathrm{C}$, GLC analysis of a hydrolyzed aliquot showed that less than $5 \%$ of the iodide remained, while an iodolysis of a reaction aliquot gave $64 \%$ reformation of the iodide. The reaction mixture was allowed to settle, and the supernatent solution of the organozinc iodide $3 \mathrm{~g}$.was cannulated into a solution of dry $\mathrm{LiCl}$ (dried for $1 \mathrm{~h}$ at $120^{\circ} \mathrm{C}$ at $0.1 \mathrm{mmHg} ; 0.42 \mathrm{~g} ; 10 \mathrm{mmol}$ ) and $\mathrm{CuCN}(0.45 \mathrm{~g}, 5 \mathrm{mmol}$ ) in $6 \mathrm{~mL}$ of THF at -70 ${ }^{\circ} \mathrm{C}$. The resulting yellow-green suspension was warmed to $0^{\circ} \mathrm{C}$ and stirred for $15 \mathrm{~min}$. After cooling to $-70^{\circ} \mathrm{C}$, a solution of tert-butyl $\alpha$-(bromomethyl) acrylate $(0.35 \mathrm{~g} ; 1.73 \mathrm{mmol}$ ) was added and the reaction was allowed to warm to $0{ }^{\circ} \mathrm{C}$ and worked up as usual after $1 \mathrm{~h}$ at this temperature. Flash-chromatographical purification of the residue (hexane:ethyl acetate 50:1) provided $467 \mathrm{mg}(72 \%)$ of $4 \mathrm{~m}$ as an analytically pure compound. 